\title{
Evaluation of Thyroid Hormones Levels in Libyan Patients with Chronic Renal Failure before and after Maintenance Hemodialysis
}

\author{
Riad M. Abughalia, Milad A. Alrzini, Karima R. Zarug Edawib \\ Higher Institute for Science \& Medical Technologies, Misallata, Libya \\ Email: idress174@gmail.com
}

How to cite this paper: Abughalia, R.M., Alrzini, M.A. and Edawib, K.R.Z. (2021) Evaluation of Thyroid Hormones Levels in Libyan Patients with Chronic Renal Failure before and after Maintenance Hemodialysis. Open Journal of Applied Sciences, 11, 11-20.

https://doi.org/10.4236/ojapps.2021.111002

Received: September 14, 2020

Accepted: January 8, 2021

Published: January 11, 2021

Copyright $\odot 2021$ by author(s) and Scientific Research Publishing Inc. This work is licensed under the Creative Commons Attribution International License (CC BY 4.0).

http://creativecommons.org/licenses/by/4.0/

(c) (i) Open Access

\begin{abstract}
Data from recent studies revealed that kidney diseases might affect the thyroid function in various ways. A variety of alterations in thyroid hormone levels and metabolism have also been reported in patients with chronic renal failure (CRF) in some studied population. In addition, it was reported that serum levels of both T3 and T4 might alter immediately after a hemodialysis (HD) treatment than before. Therefore, this study was aimed to investigate the level of triiodothyronine (T3) and thyroxine (T4) in CRF Libyan patients before and after HD. This study was carried out on 46 CRF patients ( 30 males and 16 females) with a mean age of $47.46 \pm 15.75$ years. These patients were treated at the hemodialysis unit of Educational Central Zelitin Hospital, Zelitin, Libya. None of these patients apparently have any thyroid problems and no history of drug intake that may affect thyroid function. Blood samples were taken from each patient to measure serum levels of $\mathrm{T} 3$ and $\mathrm{T} 4$, before and after HD. In addition, the effects of several variables including age, gender, body mass index (BMI), presence of both hypertension and, diabetes mellitus and duration of kidney dialysis on serum levels of T3 and T4 before and after $\mathrm{HD}$ were also studied. After HD, there was a statistically significant increase in the serum levels of T3, T4. The age, gender, BMI, duration of kidney dialysis and the presence of hypertension and diabetes mellitus did not have any significant effect on the serum level of T3 and T4 before and after HD. However, the serum levels of T3 and T4 were still in the normal range in these examined patients either before or after HD. From these findings, it can be concluded that these CRF patients may be in a euthyroid state, because the serum levels of $\mathrm{T} 3$ and $\mathrm{T} 4$ were in the normal range. In addition, HD was seemed to improve the T3 and T4 thyroid hormone concentrations, suggesting that $\mathrm{HD}$ might activate the secretion of thyroid gland and catabolism. The other variables did not play any role in thyroid hormone levels in these patients either before or after HD. It is highly recommended that large scale
\end{abstract}


evaluation of thyroid hormone levels in Libyan CRF patients is performed by more patients, especially elderly patients.

\section{Keywords}

Chronic Renal Failure (CRF), Hemodialysis (HD), Triiodothyronine (T3) and Thyroxine (T4)

\section{Introduction}

The interaction between thyroid gland and the kidney in each other's functions is known for many years [1]. Thyroid dysfunction affects renal physiology and development, whereas kidney disease could result in thyroid dysfunction. The kidney normally plays an important role in the metabolism, degradation and excretion of several thyroid hormones. [2].

Thyroid gland is the largest endocrine gland in vertebrates located in the front of the neck, and just below the larynx. Thyroid glands can synthesize three important hormones, known as thyroxine (T4), triiodothyronine (T3) and calcitonin [3]. T4 and T3 are necessary for the normal growth, development, differentiation, and stimulate the rate of metabolism in most body tissue [4] [5]. Calcitonin is a potent hypocalcemic hormone, thought until recently to act predominantly on bone to inhibit osteoclastic bone resorption. There is also evidence for an action in the kidney to decrease tubular reabsorption of calcium, and in the brain and hypothalamus, where a number of actions have been reported [6].

Kidney function might be influenced or impaired by various factors, including infections, poisoning, tumors, stone formation and others [7] [8]. These factors might cause a decline in kidney function, and/or lead to kidney diseases or renal failure.

Renal failure is one of the most serious consequences of kidney diseases. Renal failure is a situation when the kidneys fail to function effectively and unable to maintain homeostasis of the blood. It can be divided into two forms: acute and chronic renal failure [9]. Whereas, there are other factors which may help to differentiate acute and chronic kidney disease including; the presence of anemia and the kidney size on ultrasound. Chronic kidney disease generally leads to anemia and small kidney size [10].

Patients with chronic renal failure (CRF) often have signs and symptoms indicative of thyroid dysfunction. These discoveries include dry skin, sallow complexion, low temperature, cold intolerance, decreased basal metabolic rate, sleep and tiredness. Various studies of thyroid functions in uremic patients have been carried out which have shown conflicting results [11].

However, CRF disease affects thyroid function in multiple ways, including low levels of circulating thyroid hormone concentration, altered peripheral hormone metabolism, disturbed binding to carrier proteins, possible reduction in tissue thyroid hormone content and increased iodine stores in the thyroid gland [12]. Thus, patients with renal failure may have various abnormalities of thyroid 
function nevertheless; they are typically clinically euthyroid [13].

The aim of the present study was to evaluate the serum levels of thyroid hormones T3 and T4 levels in Zeletin city patients with chronic renal failure, before and after haemodialysis (HD).

\section{Objective of Research}

Several factors have been shown to influence the results of thyroid function tests. These include the type of kidney diseases, the degree and duration of renal failure, the extent of malnutrition, diabetes mellitus, dietary factors, HD with heparin or CAPD, and renal transplantation [14] [15] [16]. Taken together, it appears from these previous studies, there is an evidence of relationship between the level of thyroid hormones and CRF. However, the issue of thyroid function in patients with CRF is still inconclusive due to the complexity of the system studied. Therefore, the goal of this research will be to examine the status of thyroid function in Zeletin city patients with CRF before and after the HD. According to our knowledge this study is the first study conducted on the Zeletin city populations.

\section{Materials and Methods}

\subsection{Study Sample}

Forty six Libyan CRF patients from Zeletin City were invited to participate in this study. The subjects were invited by using multistage, stratified cluster sampling by the gender (male and female) and age groups ( $\leq 40,41-65$, and $>65$ and years). Totally 46 patients ( 30 males and 16 females) where, apparently don't have any thyroid problems and no history of drug intake that affects thyroid function (e.g. beta blockers, thyroid hormone replacement therapy, thiouracil, neomercazole) were recruited to participate in the study. The verbal consents were obtained from each individual after explaining the aims and methods of this study.

\subsection{Data Collection}

Personal and socio-demographic data from the volunteers were collected in structured questionnaires consist of a series of questions. Gender, age, height, body weight, history of health problems were included in questionnaires (diabetes, blood pressure, and other diseases). Furthermore, the subjects were asked about the period of using HD treatment.

\subsection{Blood Collection}

Blood were collected from the volunteers of Libyan in Zelitin city. Five milliliters of venous blood was withdrawn before and after HD treatment from each recruited patient. The blood samples were taken in Serum-Separating Tubes (SSTs). That tube was used to provide the serum for measuring T3 and T4 hormones. However, the Libyan blood samples were collected in the hemodialysis unit of Educational Central Zelitin Hospital, and then kept at $4^{\circ} \mathrm{C}$ before transferred to their diagnostic lab. 


\subsection{Biochemical Analysis}

The serum was separated from the blood samples. The samples were centrifuged at $3000 \mathrm{rpm}$ for $5 \mathrm{~min}$ at $4^{\circ} \mathrm{C}$. Serum total $\mathrm{T} 3$ and $\mathrm{T} 4$ hormone concentrations were assayed by Microparticle Enzyme Immunoassay (MEIA) using Abbott AxSYM system (AxSYM, Abbott Diagnostics, Abbott Park, IL), fully automated immunoassay analyzer and commercially available kits from Abbott, USA at Educational Central Zelitin Hospital lab in Libya.

\subsection{Dependant and Independent Variables}

Dependent variable: The level of T3 $(\mathrm{ng} / \mathrm{ml})$ in the blood was measured and divided into three main groups; under normal $(<0.45)$, Normal $(0.45-1.37)$, and Above normal $(>1.37)$. The serum $\mathrm{T} 4(\mu \mathrm{g} / \mathrm{dl})$ level was measured and divided into three main groups: Under normal $(<4.5)$, Normal $(4.5-12.0)$ and above normal $(>12.0)$.

Independent variables: The following variables are identified to be predictors for thyroid functional hormone among the study patients:

Age: It was divided into three groups as the following: $(\leq 40,41-65$, and $>65$ and years).

Gender: Male or female.

Body mass index (BMI): After measuring the height (meter) and body weight $(\mathrm{Kg})$ of each patient, BMI was calculated for each subject by using the following formula $\left(\mathrm{BMI}=\right.$ weight $\left./ \mathrm{Kg} /(\text { height } / \mathrm{m})^{2}\right)$ then it was divided into four categories as the following; (<19: Under weight, 19 - 25: Normal, $>25$ - 29.9: Overweight, $\geq 30$ : Obese).

Diabetes: No or Yes.

Blood pressure: No or Yes.

Duration of kidney dialysis (Years): It was divided into three groups as the following: $(\leq 4,5-9$ and $\geq 10)$.

\subsection{Data Processing and Statistical Analysis}

Data were entered and analyzed by the Statistical Package for Social Sciences (SPSS) software version 11.0 (SPSS ${ }^{\oplus}$ : Inc., Chicago, IL, USA). Normality test was done to check the data. Percentages, cross tabulation, means and standard deviations were produced and calculated. In addition, McNemar-test was used for comparisons among paired dichotomous groups and Paired $t$ test used for paired continuous parametric variables. Chi square test also was used to do comparison between before and after $\mathrm{HD}$ for Zelitin patients regarding the levels of T3 and T4 hormones. The level of significance was set at $(\mathrm{P} \leq 0.05)$.

\section{Results}

\subsection{Introduction}

The patients included in this study are 46 CRF patients from Zelitin city in Libya and their age, sex, duration of HD, BMI, presence or absence of both high blood 
pressure and diabetes mellitus were investigated. thyroid hormones (T3 and $\mathrm{T} 4$ ) were measured for all of these patients before and after of hemodalysis (HD).

\subsection{Characteristic of Studied Patients}

The samples consist of 30 males forming $65.2 \%$ and 16 females forming $34.8 \%$. Their ages ranged from 20 to 90 years. The samples divided into three groups as shown in Table 1.

\subsection{Medical History of Sample}

In current study, CRF patients of Zelitin were suffered from additional diseases. Whereas, 10 persons (12.7\%) were suffered from diabetes mellitus and 34 persons $(73.9 \%)$ were had hypertension. The duration of kidney dialysis among the studied patients is different and was divided into three groups; 1 to 4 years, 5 to 9 years, and more than 10 years. The mean and SD value of duration of kidney dialysis was 6.76 and 4.18 years, respectively (Table 2).

Table 1. Distribution of socio-demographic and personal data of sample $(\mathrm{N}=46)$.

\begin{tabular}{lc}
\hline \multicolumn{1}{c}{ Variable } & Libyan $(\mathrm{N}=46) \mathrm{N}(\%)$ \\
\hline Age & \\
$\leq 40$ & $16(34.8)$ \\
$41-65$ & $25(54.3)$ \\
$>65$ & $5(10.9)$ \\
Mean \pm SD & $(47.28 \pm 14.79)$ \\
\hline Gender & \\
Male & $30(65.2)$ \\
Female & $16(34.8)$ \\
\hline BMI & \\
Under weight $(<19)$ & $7(15.2)$ \\
Normal $(19-25)$ & $20(43.5)$ \\
Over weight $(>25-29.9)$ & $10(21.7)$ \\
Obese $(\geq 30)$ & $9(19.6)$ \\
\hline
\end{tabular}

Table 2. Distribution of medical history of sample $(\mathrm{N}=46)$.

\begin{tabular}{lc}
\hline \multicolumn{1}{c}{ Variable } & Libyan $(\mathbf{N}=46) \mathbf{N}(\%)$ \\
\hline $\begin{array}{l}\text { Diabetes mellitus } \\
\text { Yes }\end{array}$ & $10(21.7)$ \\
No & $36(78.3)$ \\
\hline Hypertension & \\
Yes & $34(73.9)$ \\
No & $12(26.1)$ \\
\hline Duration of kidney dialysis (Years) & \\
$\leq 4$ years & $17(37.0)$ \\
$5-9$ & $18(39.1)$ \\
$\geq 10$ & $11(23.9)$ \\
Mean \pm SD & $(6.76 \pm 4.18)$ \\
\hline
\end{tabular}




\subsection{The Hormonal Status at Times before and after HD Samples}

Table 3 shows the mean serum levels of T3 and T4 hormones for the 46 patients with CRF, before and after HD. The mean serum levels of T3 were $110 \mathrm{ng} / \mathrm{ml}$ and $121 \mathrm{ng} / \mathrm{dl}$ before and after HD, respectively. This study also revealed that 34 patients were had normal serum level of T3 (45 - $137 \mathrm{ng} / \mathrm{dl}$ ) before HD, but their number decreased to become 29 patients after HD. In addition, before HD, the serum level of T3 in 2 cases was lower than the normal range and 10 cases were higher than the normal range. After HD, only 1 case had serum level of T3 lower than the normal range and 16 cases had serum level of T3 above the normal range. Statistically, the mean values of serum level of T3 in patients with CRF showed significant change after HD $(\mathrm{P}<0.05)$.

Furthermore, of the $46 \mathrm{HD}$ patients with CRF entered in the study, the mean values of serum level of T4 were $4.5 \mu \mathrm{g} / \mathrm{dl}$ before HD and $5.9 \mu \mathrm{g} / \mathrm{dl}$ after HD. The number of the patients before HD who had normal serum level of T4 (4.5 - 12.0 $\mu \mathrm{g} / \mathrm{dl})$ were 19 (41\%) patients and this number had increased to 41 (89\%) patients after HD. Whereas, the number of the patients who had under normal serum level of T4 before HD were decreased from 27 (58.7\%) to 5 (10.9\%) (Table 3). Statistical analysis revealed that there was a significant difference on the mean serum levels of T4 in CRF Libyan patients before and after HD $(\mathrm{P}<0.001)$.

Table 3. The serum levels of T3 and T4 hormones in 46 patients with chronic renal failure, before and after HD.

\begin{tabular}{|c|c|c|c|}
\hline \multirow{3}{*}{ Variable } & \multicolumn{2}{|c|}{ Patients } & \multirow{3}{*}{$\mathrm{P}$-value } \\
\hline & Before HD & After HD & \\
\hline & $\mathrm{N}(\%)$ & $\mathrm{N}(\%)$ & \\
\hline T3 (ng/dl) & & & $\mathrm{P}<0.05$ \\
\hline Under normal $(<45)$ & $2(4.3)$ & $1(2.2)$ & \\
\hline Normal (45 - 137) & $34(73.9)$ & $29(63.0)$ & \\
\hline Above normal (>137) & $10(21.7)$ & $16(34.8)$ & \\
\hline Mean \pm SD of T3 level & $110.0 \pm 32$ & $121.0 \pm 37$ & \\
\hline $\mathrm{T} 4(\mu \mathrm{g} / \mathrm{dl})$ & & & $\mathrm{P}<0.01$ \\
\hline Under normal $(<4.5)$ & $27(58.7)$ & $5(10.9)$ & \\
\hline Normal (4.5 - 12.0) & $19(41.3)$ & $41(89.1)$ & \\
\hline Above normal $(>12)$ & 0 & 0 & \\
\hline Mean \pm SD of T4 level & $4.5 \pm 1.14$ & $5.9 \pm 1.31$ & \\
\hline
\end{tabular}

Data are shown as N (\%). Patients are divided into two subgroups on the basis of T3 and T4 level: under normal, normal, above normal. Significant differences were observed on serum level of T3 and T4 before and after HD.

\section{Discussion}

The serum thyroid hormone was used as indicator to determine the level of the hormones both before and after the kidney dialysis. The thyroid hormones level; T3 and T4 were analyzed and measured for all recruited patients in the study 
from Zelitin city in Libya. large number of hormonal systems are affected by CRF, until now CRF disease remains unclear to what extent these changes are responsible for aspects of uraemic syndrome. Patients with CRF often have signs and symptoms suggestive of thyroid dysfunction. Therefore, the diagnoses of thyroid disease in these patients have obvious prognostic implications [11].

In this study, 29 (63\%) out of 46 cases of patients were had normal serum levels of T3 after HD and 41 (89\%) out of 46 cases had normal serum levels of T4 after HD. The mean value before and after HD for T3 level in patients were $110 \pm$ $32 \mathrm{ng} / \mathrm{dl}$ and $121 \pm 37 \mathrm{ng} / \mathrm{dl}$, respectively. Similarly, the mean values of serum level of T4 were $4.5 \mu \mathrm{g} / \mathrm{dl}$ before HD and $5.9 \mu \mathrm{g} / \mathrm{dl}$ after HD. There was a significant change in serum levels of T3 and T4 before and after HD. Taken together, our data revealed that the HD treatment increase the serum levels of both T3 and T4 hormones. Based on these data, it is possible to suggest that HD might activate the secretion of thyroid gland and catabolism. This can be explained by the normal negative feedback regulation of the pituitary thyroid axis or the thyroid hormones and thyrotropes form a negative feedback loop. This means when the serum level of T3 and T4 increase, the production of TSH must decrease, because of no need to stimulate thyroid gland to secret more T3 and T4 hormone.

Taken together, HD seem to contribute positively to the thyroid function, because the serum levels of T3 and T4 in most of patients included in this study were in the normal range after HD. Uremia has been reported to cause a reduction in peripheral conversion of $\mathrm{T} 4$ to $\mathrm{T} 3$, producing a functionally hypothyroid state [17]. On other hand, a previous study done by El-Reshaid and colleagues showed that, after iron depletion, thyroid abnormalities improved in 8 cases out of 9 cases in patients with iron overload [18]. Based on these data, it is possible to suggest that regular HD treatment may also lower morbidity and mortality among Zeletin city patients with CRF.

The opposite of our finding was illustrated by Hershman et al. They reported a decrease in serum T4 hormone level after HD [19]. Similarly, two later studies done by Kayima et al. and by Hardy et al. reported that patients with CRF had low serum levels of T4 in adults after HD [20] [21]. In addition, Xess and coworkers also reported that patients with CRF had significant decrease in total T3 level [22]. These reports indicated that the CRF patients were in a subclinical hypothyroid state. It has been suggested that the low serum T3 levels is due to presence of dialyzable toxins in uremic plasma that might impair $\mathrm{T} 3$ transcriptional activity or extra-thyroidal T4 to T3 conversion [23]. While the low level of T4 is due to the presence of circulating inhibitors.

In agreement with our study, it had been demonstrated that TSH level on CRF Japanese patients were not significantly changed before and after HD [24]. Shamsadini and colleagues demonstrated that there was a significant change in serum levels of T3 and T4 before and after HD in 57 Iranian patients with CRF [25]. Similarly, Alsaran et al. also reported that there was a significant difference in free-T3 and free-T4 hormone levels before and after HD and no significant 
difference between before and after HD for TSH level in 40 Saudi Arabia patients with end stage renal disease [26].

This study provides an evidence that the presence of diabetes mellitus and hypertension showed no effect on serum levels of T3 and T4 in CRF patients before and after HD. Similarly, the duration of HD exhibited no effect on serum levels of T3 and T4 in CRF patients before and after HD. By contrast, In addition, a study conducted by Zoccali et al. concluded that low FT3 is frequently shown in inflammatory illnesses, and the similar association also observed in chronic kidney disease patients as well as in patients with end stage renal disease [27]. Thus, these findings suggested that these variable factors such as presence diabetes mellitus, hypertension or duration of HD did not contribute to change that observed in levels of thyroid hormones.

\section{Conclusions}

The results of the present study demonstrated that some Libyan CRF patients had serum levels of T3 and T4 lower than the serum normal range before HD, then after HD, they had normal serum levels of T3 and T4 hormones. For this reason we conclude, there is a novel interaction of kidney with thyroid hormones in patients with CRF. Also, HD might participate in the regulation of thyroid hormone synthesis (T3 and T4). On the other hand, thyroid gland levels seem to be dependent on renal function.

However, the results of the present study demonstrate that most CRF patients have lower than the normal range of $\mathrm{T} 3$ and $\mathrm{T} 4$ hormones before kidney dialysis, then after kidney dialysis they have normal levels of $\mathrm{T} 3$ and $\mathrm{T} 4$ hormones.

Finally, kidney dialysis may have a positive feedback effect on thyroid gland secretions. The thyroid gland hormones increase catabolic activities resulting in an increase in T3 and T4 hormone levels, which in turn switch off the secretion of thyroid hormones by a feedback mechanism.

\section{Acknowledgements}

Above all we are grateful to Allah who granted us the strength and patience throughout our research until the completion of this work. We wish to thank all those who helped us to complete our thesis. Special thanks to the Educational Central Zelitin Hospital administration in Libya for helping us to make this study in the hospital lab. Our gratitude also goes to the Robia Company for helping us to provide the reagents to do this research.

\section{Conflicts of Interest}

The authors declare no conflicts of interest regarding the publication of this paper.

\section{References}

[1] Kaptein, E.M., Feinstein, E.I., Nicoloff, J.T. and Massry, S.G. (1983) Serum Reverse Triiodothyronine and Thyroxine Kinetics in Patients with Chronic Renal Failure. 
The Journal of Clinical Endocrinology and Metabolism, 57, 181-189. https://doi.org/10.1210/jcem-57-1-181

[2] Jolanta, M., Malyszko, J., Wolczynski, S. and Mysliwiec, M. (2006) Adiponectin, Leptin and Thyroid Hormones in Patients with Chronic Renal Failure and on Renal Replacement Therapy: Are They Related? Nephrology Dialysis Transplantation, 21, 145-152. https://doi.org/10.1093/ndt/gfi081

[3] Kenneth, A., Ain, K., Sara, M. and Rosenthal, S. (2005) Thyroid Gland-Diseases. McGraw-Hill, New York.

[4] Vargas, F., Moreno, J., Rodríguez-Gómez, I., Wangensteen, R., Osuna, A., Alvarez-Guerra, M. and García-Estañ, J. (2006) Vascular and Renal Function in Experimental Thyroid Disorders. European Journal of Endocrinology, 154, 197-212. https://doi.org/10.1530/eje.1.02093

[5] Katyare, S., Modi, H., Patel, S. and Patel, M. (2007) Thyroid Hormone-Induced Alterations in Membrane Structure-Function Relationships: Studies on Kinetic Properties of Rat Kidney Microsomal $\mathrm{Na}(+), \mathrm{K}(+)$-ATPase and Lipid/Phospholipid Profiles. The Journal of Membrane Biology, 219, 71-81. https://doi.org/10.1007/s00232-007-9063-7

[6] Rachel, A.D. and David, M.F. (2013) Calcitonin: Physiology or Fantasy?. Journal of Bone and Mineral Research, 28, 973-979. https://doi.org/10.1002/jbmr.1869

[7] Kutlay, S., Atli, T., Koseogullari, O., Nergizoglu, G., Duman, N. and Gullu, S. (2005) Thyroid Disorders in Hemodialysis Patients in an Iodine-Deficient Community. Artificial Organs, 29, 329-332. https://doi.org/10.1111/j.1525-1594.2005.29055.x

[8] Singh, P., Bobby, Z., Selvaraj, N. and Vinayagamoorthi, R. (2006) An Evaluation of Thyroid Hormone Status and Oxidative Stress in Dialyzed Chronic Renal Failure Patients. Indian Journal of Physiology and Pharmacology, 50, 279-284.

[9] Alpern, R. and Sakhaee, K. (1997) The Clinical Spectrum of Chronic Metabolic Acidosis: Homeostatic Mechanisms Produce Significant Morbidity. The American Journal of Kidney Diseases, 29, 291-302. https://doi.org/10.1016/S0272-6386(97)90045-7

[10] Kaufman, J., Dhakal, M., Patel, B. and Hamburger, R. (1991) Community-Acquired Acute Renal Failure. The American Journal of Kidney Diseases, 17, 191-198. https://doi.org/10.1016/S0272-6386(12)81128-0

[11] Avasthi, G., Malhotra, S., Narang, A. and Sengupta, S. (2001) Study of Thyroid Function in Patients of Chronic Renal Failure. Indian Journal of Nephrology, 11, 165-169.

[12] Lim, V.S. (2001) Thyroid Function in Patients with Chronic Renal Failure. The American Journal of Kidney Diseases, 38, S80-S84. https://doi.org/10.1053/ajkd.2001.27410

[13] Thysen, B., Gatz, M., Freeman, R., Alpert, B.E. and Charytan, C. (1983) Serum Thyroid Hormone Levels in Patients on Continuous Ambulatory Peritoneal Dialysis and Regular Hemodialysis. Nephron, 33, 49-52. https://doi.org/10.1159/000182904

[14] La, S. (1991) Thyroid Function in Children with Chronic Renal Failure. The Journal of Pediatrics, 118, 896-898. https://doi.org/10.1016/S0022-3476(05)82201-2

[15] Francisco, M. (2008) Kidney Failure in the Elderly Due to Hypothyroidism: A Case Report. Sao Paulo Medical Journal, 126, 291-393. https://doi.org/10.1590/S1516-31802008000500010

[16] Iglesias, P. and Díez, J. (2009) Thyroid Dysfunction and Kidney Disease. European Journal of Endocrinology, 160, 503-515. https://doi.org/10.1530/EJE-08-0837 
[17] Drabczyk, R., Grzeszczak, W. and Trelewicz, P. (1992) Influence of Long Term Hemodialysis Treatment on TSH Secretion in Patients with Chronic Renal Failure. Polskie Archiwum Medycyny Wewnetrznej, 88, 381-91.

[18] El-Reshaid, K., Seshadri, M., Hourani, H., Qurtom, M. and Kamel, H. (1995) Endocrine Abnormalities in Hemodialysis Patients with Iron Overload: Reversal with Iron Depletion. Nutrition, 11, 521-526.

[19] Hershman, J., Krugman, L., Kopple, J., Reed, A., Azukizawa, M. and Shinaberger, J. (1978) Thyroid Function in Patients Undergoing Maintenance Hemodialysis: Unexplained Low Serum Thyroxine Concentration. Metabolism, 27, 755-759. https://doi.org/10.1016/0026-0495(78)90209-3

[20] Kayima, J.K., Otieno, L.S., Gitau, W. and Mwai, S. (1992) Thyroid Hormone Profiles in Patients with Chronic Renal Failure on Conservative Management and Regular Hemodialysis. East African Medical Journal, 69, 333-336.

[21] Hardy, M.J., Ragbeer, S.S. and Nascimento, L. (2001) Pituitary-Thyroid Function in Chronic Renal Failure Assessed by a Highly Sensitive Thyrotropin Assay. The Journal of Clinical Endocrinology and Metabolism, 66, 233-236. https://doi.org/10.1210/jcem-66-1-233

[22] Xess, A., Gupta, A., Kumar, U., Sharma, H.P. and Prasad, K.M. (1999) Evaluation of Thyroid Hormones in Chronic Renal Failure. Indian Journal of Pathology \& Microbiology, 42, 129-133.

[23] Ramirez, G., O’Neill, W., Jubiz, W. and Bloomer, H.A. (1976) Thyroid Dysfunction in Uremia: Evidence for Thyroid and Hypophyseal Abnormalities. Annals of Internal Medicine, 84, 672-676. https://doi.org/10.7326/0003-4819-84-6-672

[24] Sakurai, S., Hara, Y., Miura, S., et al. (1988) Thyroid Functions before and after Maintenance Hemodialysis in Patients with Chronic Renal Failure. Endocrinologia Japonica, 35, 865-876.

[25] Shamsadini, S., Darvish-Moghaddam, S., Abdollahi, H., Fekri, A. and Ebrahimi, H. (2006) Creatinine, Blood Urea Nitrogen and Thyroid Hormone Levels before and after Haemodialysis. Eastern Mediterranean Health Journal, 12, 231-235.

[26] Alsaran, K., Sabry, A., Alshahhat, H., Babgy, E. and Alzahrani, F. (2011) Free Thyroxine, Free Triiodothyronine and Thyroid-Stimulating Hormone before and after Hemodialysis in Saudi Patients with End-Stage Renal Disease: Is There Any Difference? Saudi Journal of Kidney Disease and Transplantation, 22, 917-921.

[27] Zoccali, C., Tripepi, G., Cutrupi, S., Pizzini, P. and Mallamaci, F. (2005) Low Triiodothyronine: A New Facet of Inflammation in End-Stage Renal Disease. Journal of the American Society of Nephrology, 16, 2789-2795.

https://doi.org/10.1681/ASN.2005040356 